\title{
Estratégias de compreensão leitora: uma proposta de atividades desenvolvidas sob a perspectiva das metodologias ativas de ensino
}

Reading strategies: a proposal of activities developed under the perspective of active teaching methodologies

Estrategias de comprensión lectora: una propuesta de actividades desarrolladas bajo la perspectiva de las metodologías activas de enseñanza

\section{Aline Diesel, Silvana Neumann Martins, Márcia Jussara Hepp Rehfeldt ${ }^{*}$}

\section{Resumo}

Este estudo se propõe a investigar como um acervo didático, elaborado à luz das metodologias ativas e voltado para o ensino de estratégias de leitura, pode contribuir para o aprimoramento da compreensão leitora de alunos do 5 o e do 8 o anos de uma escola municipal. Nesse viés, a pesquisa configurou-se em uma abordagem qualiquantitativa, em que os alunos foram submetidos a um pré e um pós-teste cloze, realizados antes e após a 
interação com um acervo didático. O tratamento dos dados coletados seguiu a avaliação quantitativa. Como resultados, constatou-se que, após a interação com o acervo didático, o percentual de evolução do 5 음 ano foi de $23,4 \%$, ao passo que a evolução do 8 o ano foi de $12,05 \%$. Esses dados são significativos em relação ao pouco tempo de interação com o material, validando a pertinência do ensino de estratégias de compreensão leitora numa perspectiva das metodologias ativas de ensino.

Palavras-chave: Estratégias de leitura. Metodologias ativas de ensino. Acervo didático.

\section{Abstract}

This study proposes to investigate how a didactic collection elaborated in the light of active methodologies and aimed at teaching reading strategies may contribute towards the enhancement of reading comprehension with students from the 5th and 8th years at a municipal school. Towards this sense, the research has been configured within a quali-quantitative approach in which students underwent cloze pre-and post-tests applied before and after interaction with a didactic collection. Treatment of the collected data followed a quantitative evaluation. It was found that following the interaction with the didactic collection, the evolution percentage for the 5 th year was of $23.4 \%$, whereas that of the 8 th year was of $12.05 \%$. These data are meaningful when related to the short time of interaction with the material, thus validating the pertinence of teaching reading comprehension strategies under the perspective of active teaching methodologies.

Keywords: Reading Strategies. Active Teaching Methodologies. Didactic Collection.

\section{Resumen}

Este estudio se propone investigar cómo un acervo didáctico, elaborado a la luz de las metodologías activas y orientado hacia la enseñanza de estrategias de lectura, puede contribuir para el perfeccionamiento de la comprensión lectora de alumnos de 5o y 8a años de una escuela municipal. En este sentido, la investigación se configuró en un abordaje 
cuali-cuantitativo, en el que los alumnos fueron sometidos a un pre y post-test cloze, realizados antes y después de la interacción con un acervo didáctico. El tratamiento de los datos recolectados siguió la evaluación cuantitativa. Como resultados, se constató que, tras la interacción con el acervo didáctico, el porcentaje de evolución del 5 o año fue de 23,4\%, mientras que la evolución del 8 o año fue de 12,05\%. Eses datos son significativos en relación al corto tiempo de interacción con el material, validando la pertinencia de la enseñanza de estrategias de comprensión lectora en una perspectiva de las metodologías activas de enseñanza.

Palavras clave: Estrategias de lectura. Metodologías activas de enseñanza. Acervo didáctico.

\section{Introdução}

Índices oficiais sobre o desempenho em leitura dos estudantes brasileiros demonstram que essa habilidade ainda está muito aquém do ideal. A título de exemplo, pode-se mencionar o desempenho da leitura dos estudantes na Prova Brasil de 2015, avaliação realizada em âmbito nacional, que avalia a capacidade de leitura e de resolução de problemas de estudantes de $5^{\circ}$ e $9^{\circ}$ anos. Os resultados dessa avaliação revelam que a média dos estudantes brasileiros em fase de conclusão do Ensino Fundamental foi de 251,53 e a dos estudantes gaúchos foi de 256,65. Isso significa que, numa escala de proficiência que considera os níveis 1 a 9 (sendo que o nível 1 envolve habilidades mais simples, e o nível 9 envolve habilidades mais sofisticadas), esses estudantes enquadram-se no nível 6 (BRASIL, 2015).

Esses resultados evidenciam que muito ainda se tem a pesquisar, a refletir e a debater sobre o ensino da Língua Portuguesa nas escolas de modo que as práticas pedagógicas desenvolvidas nessa área auxiliem os estudantes a aprimorarem sua competência leitora e, consequentemente, a evoluírem nos índices apresentados anteriormente. Parece que muitos alunos não são ensinados a compreender de fato o texto. $O$ professor parte do pressuposto de que está ensinando a ler pelo simples fato de 
oferecer a oportunidade de o aluno decodificar e de propor-lhes perguntas de compreensão e interpretação. De acordo com Solé (1998), só isso não ensina o aluno a compreender. É preciso ter a leitura como um objeto de conhecimento, de modo a realizar intervenções que ensinem os alunos a desenvolver estratégias de leitura, como ativar o conhecimento prévio relevante, estabelecer objetivos de leitura, esclarecer dúvidas, prever, estabelecer inferências, autoquestionar, resumir, sintetizar, entre outras.

Muito comuns, também, são as inúmeras práticas pedagógicas objetivando despertar o interesse pelo gosto da leitura, afinal, trata-se de uma importante habilidade para a vida do sujeito, por lhe trazer conhecimentos. Contudo, por que será que o aluno não gosta de ler? Seria por falta de incentivo? Neste trabalho, acredita-se que o incentivo à leitura é imprescindível; contudo, antes do incentivo, deve-se ensinar estratégias de compreensão, para que os alunos saibam posicionar-se diante da leitura.

Além disso, percebe-se que, na disciplina de Língua Portuguesa no Ensino Fundamental, o ensino, muitas vezes, ainda é focado em classes e em normas gramaticais desprovidas do texto. Ou seja, os professores trabalham a gramática de forma descontextualizada, sendo o texto - quando existe, pois muitas vezes o trabalho parte de frases isoladas - apenas o pretexto para o estudo de determinada regra gramatical. Corrobora-se, neste estudo, com Porto (2011) ao considerar que a leitura deve ser tida como um objeto de aprendizagem, e não apenas um objeto de ensino.

Objetivando trazer contribuições nesse sentido, entende-se que as aulas de Língua Portuguesa na Educação Básica, especialmente no Ensino Fundamental, devem ensinar os alunos a, de fato, ler. Isso significa que se deve auxiliar os alunos a reconhecerem elementos implícitos no texto, a fazerem inferências, a reconhecerem ambiguidades e ironias. Além disso, as aulas precisam incentivar a formação de leitores para a vida. Nessa perspectiva, o ensino de normas gramaticais no Ensino Fundamental deve ficar para um segundo plano.

As metodologias ativas de ensino muito têm a contribuir nesse aspecto, já que pressupõem o envolvimento ativo dos alunos no 
aprendizado da compreensão leitora. Um leitor proficiente, ativo, significa um leitor que reflete sobre seu processo de leitura. Os recursos educacionais digitais, vistos sob o ponto de vista das metodologias ativas de ensino, também podem favorecer esse processo de construção de um leitor ativo, pois possibilitam uma postura ativa e autônoma dos estudantes. Permitem uma infinidade de possibilidades com a leitura e a escrita, por meio de softwares e aplicativos interativos.

Diante desse panorama, delineado pela pesquisadora deste estudo no decorrer da experiência profissional enquanto professora de Língua Portuguesa no Ensino Fundamental, ratifica-se a necessidade de voltar o ensino para desenvolver no aluno estratégias de leitura. Nesse sentido, foram identificados subsídios para a delimitação do tema foco desta investigação, qual seja o ensino de estratégias de compreensão leitora no Ensino Fundamental na perspectiva das metodologias ativas de ensino. Surgiu, então, o seguinte problema de pesquisa: Como um acervo didático, elaborado à luz das metodologias ativas e voltado para o ensino de estratégias de leitura, pode contribuir para o aprimoramento da compreensão leitora de alunos do $5^{\circ}$ e do $8^{\circ}$ anos de uma escola municipal?

Tal problemática suscitou a delimitação do seguinte objetivo geral: Investigar como um acervo didático, elaborado à luz das metodologias ativas e voltado para o ensino de estratégias de leitura, pode contribuir para o aprimoramento da compreensão leitora de alunos do $5^{\circ}$ e do $8^{\circ}$ anos de uma escola municipal. A investigação, de cunho qualiquantitativo, foi desenvolvida em uma escola municipal de Ensino Fundamental situada na cidade de Marques de Souza/RS. Teve como sujeitos as professoras de Língua Portuguesa do $5^{\circ}$ e do $8^{\circ}$ anos, bem como os alunos dessas turmas.

Cabe mencionar, ainda, que este trabalho é um recorte da pesquisa apresentada na dissertação intitulada Estratégias de compreensão leitora: uma proposta de atividades desenvolvidas sob a perspectiva das metodologias ativas de ensino, desenvolvido ao longo de 2016, junto ao Programa de Pós-Graduação em Ensino. Os achados desta etapa do trabalho serviram de subsídio para a elaboração das atividades voltadas para o ensino de estratégias de leitura. 


\section{Fundamentação teórica}

\section{A competência leitora e a sua importância}

Quando a leitura envolve a compreensão, ler torna-se um instrumento útil para aprender significativamente. Isso quer dizer que, de acordo com Solé (1998), a leitura aproxima os sujeitos da cultura e ao mesmo tempo contribui para que o aluno constitua-se como cidadão. Além disso, "se ensinamos um aluno a ler compreensivamente e a aprender a partir da leitura, estamos fazendo com que ele aprenda a aprender, isto é, com que ele possa aprender de forma autônoma em uma multiplicidade de situações" (SOLÉ, 1998, p. 47). Nesse sentido, a leitura possibilita que o leitor incorpore novas informações, novos conceitos, novos dados, novas ideias ou mesmo novas percepções acerca de um determinado fato.

Tais afirmações vêm ao encontro das percepções de Forneck et al. (2015, p. 7), ao considerarem que a importância de conduzir o aluno a ler com competência reside no fato de que "[...] as pessoas que sabem ler conseguem interagir com o mundo letrado de maneira muito mais eficiente, já que são capazes de, em tese, extrair de textos verbais a complexidade de sentidos evocada pelas palavras".

Além disso, é preciso considerar também que aprimorar as habilidades de leitura entre a população é um elemento que, de acordo com a percepção de Sacristán (2008), distingue notoriamente as pessoas na atual hierarquia de valores da sociedade. Em outras palavras, o valor que a leitura tem na vida das pessoas é condição para exercer sua cidadania e para a sua inclusão social. O autor ainda complementa: "A leitura é uma prática que reflete e determina uma forma de adquirir e de se relacionar com a experiência dos outros, que, na realidade, é o que nos torna verdadeiramente humanos. Somos o que lemos e como lemos" (SACRISTÁN, 2008, p. 95).

Forneck et al. (2015) coadunam com essas reflexões quando ressaltam que cabe à escola a tarefa de formar leitores competentes, mediante o estímulo à autonomia e ao desenvolvimento consciente de estratégias de compreensão leitora. A partir disso, o leitor poderá escolher a 
estratégia que melhor se aplica às situações de leitura de diversos gêneros textuais com os quais terá de lidar.

Diante disso, a noção de que a escola deve garantir que os estudantes tenham, de fato, habilidades de ler um texto tem assumido cada vez mais destaque nas discussões sobre o ensino da Língua Portuguesa, e vem ganhando espaço entre o rol de objetivos dessa área. Ruaro (2013, p. 189), seguindo essa linha de pensamento, considera que "as habilidades de leitura e de escrita precisam ser pensadas em termos de estratégias de ensino capazes de dar conta da aprendizagem significativa e também da aprendizagem reflexiva". Em outras palavras, o que o professor aborda em Língua Portuguesa precisa ter significado para o aluno de modo que o "trabalho do educador não caia no vazio da teoria e da prática e não leve o aluno a não pensar no que faz enquanto o faz".

Dessa forma, o professor de Língua Portuguesa no Ensino Fundamental deve conhecer os caminhos utilizados pelo leitor para compreender o que está lendo. Tais caminhos envolvem processos cognitivos e estratégias que ele adota para aprimorar a habilidade de leitura. Essa será a temática da próxima seção.

\section{O ensino de estratégias de compreensão leitora}

De início, convém esclarecer que aprender a ler não é fácil e dificilmente se dá de forma espontânea. Caso assim fosse, não haveria tantos analfabetos e, o que é mais grave, não teria um percentual tão elevando de analfabetos funcionais, isto é, de sujeitos que frequentaram a escola por anos e não compreendem o que leem, mesmo estando expostos a palavras escritas nos mais variados lugares ou suportes, como nas telas das televisões (MORAES, 2013).

Moraes (2013) justifica esse quadro pelo fato de não terem sido ensinados a ler. Muitos foram ensinados apenas a decodificar, mas não a ler, o que implica "estabelecer o tema, o quadro espacial e temporal das informações transmitidas, as personagens ou agentes envolvidos, a 
situação ou o conhecimento de que se parte e aqueles a que se chega" (MORAES, 2013, p. 111).

Com base nos preceitos apresentados aqui, evidencia-se que a compreensão envolve um processo cognitivo que constantemente precisa ser revisto, aumentado e atualizado a partir da leitura realizada. São procedimentos que precisam ser ensinados aos alunos, de modo que ele perceba, de acordo com Mangili (2011), os caminhos inteligentes para a compreensão leitora.

Ao tratar das estratégias de leitura, adentra-se no campo de investigação de Solé (1998, p. 71). A autora explica que o leitor proficiente utiliza as estratégias de forma inconsciente; o processamento de informação escrita que o ato de leitura requer acontece de maneira automática. Entretanto, quando encontra algum obstáculo, como uma frase incompreensível, um desenlace inesperado que contradiga as expectativas, uma página colocada de forma incorreta, o leitor proficiente dispõe uma atenção especial e realiza determinadas ações, como reler o contexto da frase, examinar as premissas em que se baseiam as previsões sobre qual deveria ser o final do romance, entre outras. Nesse caso, o leitor utiliza-se de estratégias de forma completamente consciente.

É possível delimitar o papel das estratégias na esfera do ensino da leitura como um conjunto de ações executadas pelo leitor durante o processo de leitura. Podem ser classificadas em estratégias cognitivas e em estratégias metacognitivas. Estratégias cognitivas em leitura designam os princípios que regem o comportamento automático e inconsciente do leitor (KATO, 1985). Em outras palavras, ainda seguindo a ideia de Kato (1985), as estratégias cognitivas munem o leitor de procedimentos eficazes e econômicos, responsáveis pelo processamento automático e inconsciente da leitura, enquanto que as metacognitivas orientam o uso das estratégias para desautomatizá-las em situações de problemas de leitura.

Uma das características fundamentais do processo metacognitivo da leitura é a capacidade que o leitor possui de avaliar a qualidade da própria compreensão. Isso significa que o leitor deve perceber quando está entendendo bem um texto, quando a compreensão está sendo parcial ou quando o texto não lhe faz sentido (LEFFA, 1996). Mas não é só isso: 
um leitor proficiente sabe o que fazer quando está tendo problemas de compreensão. "Sabe até que ponto está ou não preparado para atender as exigências encontradas, qual é a tarefa necessária para resolver o problema e, o que é mais importante, se o esforço a ser dispendido vale ou não a pena em função dos possíveis resultados" (LEFFA, 1996, p. 45).

Dada a complexidade que permeia o ato de ler, defende-se que o trabalho do professor em sala de aula deve priorizar o ensino dessas estratégias de modo que o leitor tenha consciência de seu processo de leitura, identificando problemas de compreensão e sendo capaz de encontrar soluções para os problemas de leitura, assim que eles ocorrerem. Em síntese, o trabalho em sala de aula deve formar leitores autônomos, capazes de compreenderem diversos textos, sejam eles difíceis, criativos, ou mal escritos (SOLÉ, 1998).

A autora classifica as estratégias em três grupos: estratégias antes da leitura, estratégias durante a leitura e estratégias após a leitura (Quadro 1). Contudo, ela mesma garante que essa divisão é meramente didática, já que muitas estratégias podem ocorrer praticamente simultaneamente.

Quadro 1 - Estratégia de leitura, a partir da classificação sugerida por Solé (1998)

\begin{tabular}{lll}
\hline Estratégias antes da leitura & Estratégias durante a leitura & Estratégias após a leitura \\
\hline a) Motivação & a) Fluência na leitura & a) Identificação da ideia \\
b) Definição de um objetivo de & b) Autorregulação & principal \\
leitura & c) Autoavaliação & b) Sumarização \\
c) Ativação de conhecimentos & d) Inferência & \\
prévios & e) Predição & \\
d) Previsões sobre o texto & & \\
\hline
\end{tabular}

Fonte: Elaborado pelas autoras, a partir de Solé (1998).

O ensino dessas estratégias foi o foco principal do acervo didático elaborado no âmbito do estudo que aqui se apresenta. Outro aspecto levando em conta no acervo é que as atividades desenvolvidas fossem metodologias ativas de ensino, tema abordado na próxima seção. 


\section{Metodologias ativas de ensino}

No intuito de esclarecer o que se entende por uma abordagem pautada em metodologias ativas de ensino, apresenta-se a figura a seguir (Figura 1), que sintetiza seus pontos basilares, cunhados a partir dos seguintes aportes teóricos: a) o sociointeracionismo, caracterizado por Lev Vygotsky, b) a aprendizagem significativa de David Ausubel, c) a pedagogia para a autonomia e crítica, fundada em Paulo Freire, e a aprendizagem pela experiência, cunhada por John Dewey.

Figura 1 - Pontos basilares das metodologias ativas de ensino

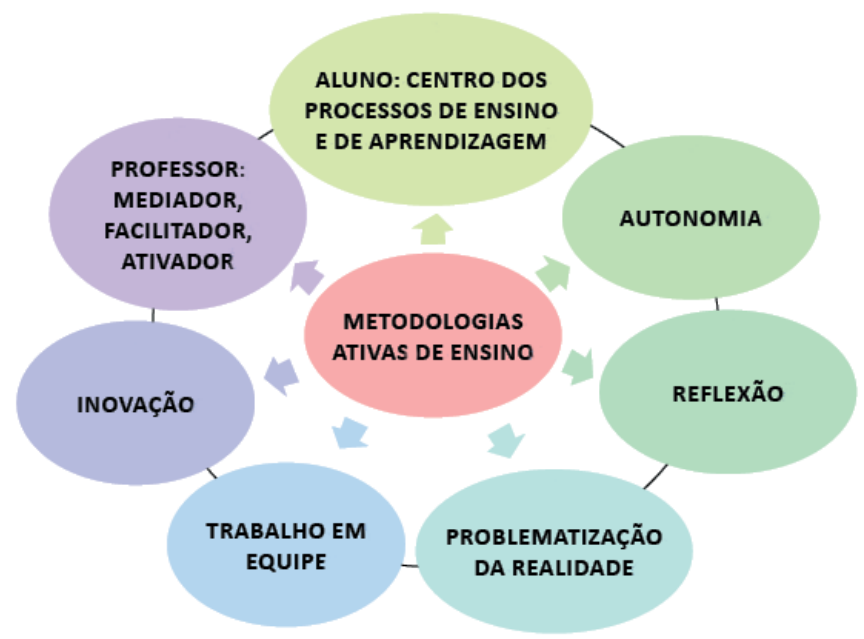

Fonte: Diesel, Marchesan e Martins (2016, p. 156).

a) Aluno: centro dos processos de ensino e de aprendizagem

$\mathrm{O}$ atual movimento dinâmico da sociedade tecnológica, em que se tem o acesso facilitado à informação, traz à tona o debate acerca do papel do aluno nos processos de ensino e de aprendizagem. O âmago do debate 
reside na postura mais central e menos secundária do estudante, de mero expectador dos conteúdos que lhe são apresentados. Nessa perspectiva de entendimento, as metodologias ativas situam-se como uma possibilidade de promover o aprendizado dos estudantes, colocando-os no centro do processo. Dessa feita, há uma "migração do 'ensinar' para o 'aprender', o desvio do foco do docente para o aluno, que assume a corresponsabilidade pelo seu aprendizado" (SOUZA; IGLESIAS; PAZIN-FILHO, 2014, p. 285).

A partir de uma maior interação do aluno no processo de construção do próprio conhecimento, que, conforme explicitado anteriormente, é a principal característica de uma abordagem de ensino por metodologias ativas, o aprendiz passa a ter mais controle e participação durante a aula, já que exigem-se dele ações e construções mentais variadas, tais como: leitura, investigação, comparação, observação, imaginação, obtenção e organização de informações coletadas, elaboração e confirmação de proposições, classificação, interpretação, crítica, construção de sínteses e aplicação de fatos e princípios a novas situações, planejamento de projetos e pesquisas, análise e tomadas de decisões (SOUZA; IGLESIAS; PAZIN-FILHO, 2014).

Entende-se que tais ações, realizadas pelo aluno quando está no centro do processo, favoreçam a aprendizagem significativa, cunhada pela teoria ausubeliana. Quando o aluno é estimulado a ler, pesquisar, comparar, observar, criticar, etc., a nova informação é relacionada de maneira substantiva e não arbitrária a um conhecimento prévio já construído pelo aluno.

\section{b) Autonomia}

No ensino tradicional, em que a prática docente é baseada prioritariamente na transmissão de conteúdos, o estudante tem uma postura passiva diante dos processos de ensino e de aprendizagem, tendo a função de receber e absorver uma quantidade enorme de informações apresentadas pelo docente. Nessa metodologia, não há espaço para o estudante manifestar-se e posicionar-se acerca da temática desenvolvida. Em oposição a isso, ao desenvolver práticas pedagógicas norteadas pelo método ativo, o estudante passa a assumir uma postura ativa (BERBEL, 2011; SOUZA; 
IGLESIAS; PAZIN-FILHO, 2014), exercitando uma atitude crítica e construtiva que fará dele um profissional mais bem preparado.

Tomado desse ângulo, está-se estimulando a postura autônoma do estudante, que é outro princípio teórico fundamental atrelado a essa abordagem. Berbel (2011, p. 29) considera que a característica da autonomia é fundamental para desempenhar funções nas diversas esferas, principalmente na profissional:

O engajamento do aluno em relação a novas aprendizagens, pela compreensão, pela escolha e pelo interesse, é condição essencial para ampliar suas possibilidades de exercitar a liberdade e a autonomia na tomada de decisões em diferentes momentos do processo que vivencia, preparando-se para o exercício profissional futuro.

Não é possível falar em autonomia na educação sem falar das ideias freirianas. Para o autor, "[...] o essencial nas relações entre educador e educando, entre autoridade e liberdades, entre pais, mães, filhos e filhas é a reinvenção do ser humano no aprendizado de sua autonomia" (FREIRE, 1996, p. 37).

\section{c) Problematização da realidade e reflexão}

No contexto da sala de aula, problematizar implica fazer uma análise sobre a realidade como forma de tomar consciência dela. Em outra instância, há necessidade de o docente instigar o desejo de aprender do estudante, problematizando os conteúdos. Reportando-se a essa questão, Hengemühle (2014) orienta que, para isso, é imprescindível que o docente conheça as situações e os problemas aos quais o conteúdo está ligado. $\mathrm{O}$ autor ainda destaca que, muitas vezes, reside aí uma dificuldade, pois nem sempre o docente consegue atender a esse requisito.

A partir disso, é possível empreender que as metodologias ativas de ensino constituem-se numa concepção educativa que estimula a postura crítica e reflexiva dos estudantes, pois os processos de ensino e de aprendizagem consideram o estudante como papel ativo e ele é 
corresponsável pelo seu próprio aprendizado. Tal perspectiva é corroborada por Medeiros (2014, p. 43), segundo o qual essa abordagem explora a

[...] construção de situações de ensino que promovam uma aproximação crítica do aluno com a realidade; a opção por problemas que geram curiosidade e desafio; a disponibilização de recursos para pesquisar problemas e soluções; bem como a identificação de soluções hipotéticas mais adequadas à situação e a aplicação dessas soluções. Além disso, o aluno deve realizar tarefas que requeiram processos mentais complexos, como análise, síntese, dedução, generalização.

Dessa forma, ao serem oportunizadas situações de aprendizagem envolvendo a problematização da realidade do aluno, nas quais o estudante tenha papel ativo como protagonista do seu processo de aprendizagem, interagindo com o conteúdo, ouvindo, falando, lendo, relendo, questionando e debatendo, estará praticando e aperfeiçoando habilidades como observar, refletir, confrontar, planejar, replanejar, entre outras. Tais práticas podem contribuir para solucionar problemas da sociedade tidos como "perdidos", como é o caso da violência, das drogas, das questões genéticas, entre outros (THEISEN, 2008).

\section{d) Trabalho em equipe}

O trabalho com metodologias ativas de ensino favorece a interação constante entre os estudantes. A aula expositiva, na qual os alunos sentam-se em carteiras individuais e em que, na maioria das vezes, não podem trocar ideias com os colegas, dá lugar a momentos de discussão e trocas. Nessa abordagem, "o ponto de partida é a prática social do aluno que, uma vez considerada, torna-se elemento de mobilização para a construção do conhecimento" (ANASTASIOU; ALVES, 2004, p. 6).

Esse movimento de interação constante com os colegas e com o professor leva o estudante a, constantemente, refletir sobre uma determinada situação, a emitir uma opinião acerca da situação, a argumentar a favor ou contra, e a expressar-se. 


\section{e) Inovação}

O termo "inovação" tem um valor significativo nesse percurso de transcender a abordagem tradicional de ensino, que privilegia unicamente metodologias de transmissão mecânica de conteúdo, em que a função do estudante é de receptor passivo. Para superar esse modelo, é preciso valorizar a inovação em sala de aula, renovando, inventando ou criando metodologias. Assim, a metodologia ativa de ensino exige, tanto do professor quanto do estudante, a ousadia para inovar no âmbito educacional.

Para tanto, é imprescindível a reflexão sobre a própria prática. Freire (1996) considera que a próxima prática pode ser melhorada se o professor pensar criticamente a prática de ontem. E complementa: "[...] quanto mais me assumo como estou sendo e percebo as razões de ser de porque estou sendo assim, mais me torno capaz de mudar, de promover-me, no caso, do estado de curiosidade ingênua para o de curiosidade epistemológica" (FREIRE, 1996, p. 18).

\section{f) Professor: mediador, facilitador, ativador}

A prática educativa possui uma importante função na formação do sujeito, posto que sua essência é formadora e de natureza ética. Nesse sentido, o saber docente institui-se numa prática cujo eixo constitutivo é a humanidade dos atores num dinâmico e complexo processo de interação. Essa perspectiva converge com a ideia da inter-relação existente entre os saberes da docência e a formação humana descrita por Freire (1996, p. 14):

Percebe-se, assim, a importância do papel do educador, o mérito da paz com que viva a certeza de que faz parte de sua tarefa docente não apenas ensinar os conteúdos, mas também ensinar a pensar certo. Daí a impossibilidade de vir a tornar-se um professor crítico se, mecanicamente memorizador, é muito mais um repetidor de frases e de ideias inertes do que um desafiador.

Em outras palavras, ensinar não significa transferir ou transmitir saberes a outro que os recebe de forma passiva. Ao contrário, significa provocar, desafiar ou ainda promover as condições de construir, refletir, 
compreender, transformar, sem perder de vista o respeito à autonomia e à dignidade deste outro, que são ações que refletem a postura de um professor que se vale de uma abordagem pautada em metodologias ativas de ensino.

Conforme mencionado nesta seção, práticas pedagógicas guiadas pelo método ativo consagram um estilo de ensino em que o aluno é o centro do processo, e não mais o professor, que se torna um mediador. Todavia, isso não significa que o seu trabalho seja diminuído e perca importância. Muito pelo contrário. Numa abordagem baseada no método ativo, o papel do professor é fundamental, pois deverá provocar os alunos a refletirem, a estabelecerem pontes com situações da realidade, a pensarem em soluções ou alternativas para resolverem determinados problemas (BERBEL, 2011).

Diante desse aparato teórico, visualizam-se as metodologias ativas não como técnicas, e sim como uma abordagem teórica que direciona o docente a planejar estratégias pedagógicas, privilegiando a centralidade do aluno no processo de aprendizagem, de modo a exercitar a autonomia, a reflexão, a problematização da realidade e o trabalho em equipe, a fim de promover uma aprendizagem significativa dos estudantes. Essa se constitui a definição de metodologias ativas neste trabalho.

Assim, entende-se aqui que um leitor ativo é o que envolve os componentes metacognitivos sobre a própria compreensão, pois, além de compreender, sabe o que compreende e quando não compreende. Ao perceber um problema na compreensão, o leitor ativo toma uma decisão segura para tentar resolver esse problema. Seguindo a perspectiva de Solé (1998), um leitor ativo é o que utiliza, de forma autônoma, as estratégias de leitura apresentadas anteriormente. Em outras palavras, ao apropriar-se de estratégias que o levarão à compreensão, poderá não somente inferir, mas encontrar respostas aos problemas que surgem durante o percurso da leitura.

\section{Procedimentos metodológicos}

Esta pesquisa possui uma abordagem qualiquantitativa, aproximando-se de alguns pressupostos teóricos da pesquisa-ação e do estudo 
de caso. Para alcançar o objetivo proposto, foi desenvolvida, no âmbito desta pesquisa, a partir do aporte teórico estudado, uma coletânea de atividades norteadas por metodologias ativas de ensino, voltadas para o ensino de estratégias de leitura. As atividades que integram essa coletânea foram apresentadas às professoras envolvidas, que deveriam possibilitar, ao menos uma vez por semana, a interação do material com os alunos, no período de abril a junho de 2016.

O cenário da pesquisa foi uma escola municipal de Ensino Fundamental localizada no município de Marques de Souza-RS/BRA. Os sujeitos envolvidos neste trabalho foram as professoras de Língua Portuguesa e os 55 alunos dos $5^{\circ}$ e dos $8^{\circ}$ anos da referida escola. Estes também assinaram o TCLE, em que os responsáveis manifestaram ciência dos passos deste trabalho e deram o consentimento da participação dos filhos. As professoras foram nomeadas por Professora 1 e Professora 2. Já os alunos do $5^{\circ}$ ano foram nomeados por A5-1, A5-2 e assim sucessivamente, e os alunos do $8^{\circ}$ ano foram nomeados por A8-1, A8-2 e assim sucessivamente.

O envolvimento dos alunos neste estudo foi na realização do pré-teste, a fim de avaliar a sua competência leitora antes da interação com as atividades desenvolvidas semanalmente. Após os três meses de aplicação das atividades, o mesmo teste foi reaplicado, permitindo verificar a evolução da habilidade de leitura. O foco desta publicação está na análise desse teste.

O pré-teste cloze (PEREIRA, 2005; 2008) foi utilizado a fim mensurar os níveis de compreensão leitora dos alunos antes do trabalho com as estratégias de compreensão leitora. Ao final do trabalho com as estratégias, foi reaplicado o mesmo teste cloze (pós-teste), possibilitando averiguar, por meio de uma análise quantitativa, se houve ou não evolução nos níveis de leitura.

De acordo com Pereira (2005) e Leffa (1996), o cloze é uma técnica de lacunamento do texto, para que as palavras omitidas sejam recuperadas pelo leitor, tendo sido utilizada mundialmente como uma forma para avaliar a proficiência em leitura. Nessa técnica, recomenda-se iniciar as lacunas a partir da terceira ou quarta linha, sendo, dali em diante apagada uma palavra para cada cinco palavras do texto (LEFFA, 1996). Para não influenciar o leitor quanto ao comprimento da palavra deletada, 
Pereira (2005) recomenda que a lacuna deve ter um espaço vazio de extensão padronizada. O texto utilizado para a aplicação do pré e pós-teste da turma do $5^{\circ}$ ano foi elaborado pela pesquisadora, seguindo algumas das orientações dos autores. Já o pré e pós-teste aplicados na turma do $8^{\circ}$ foi elaborado e validado por Pereira (2005).

O acervo didático, ou coletânea de atividades, como também é chamado, foi construído por propostas de atividades a serem desenvolvidas pelos professores em suas práticas docentes. Trata-se de uma coletânea composta por 34 atividades que objetivam desenvolver pelo menos uma estratégia de leitura dentre as mencionadas no referencial teórico deste trabalho.

Destaca-se que algumas atividades foram idealizadas e elaboradas pela pesquisadora, outras atividades foram coletadas em livros didáticos ou teóricos e, por terem sido consideradas relevantes para os propósitos deste trabalho, foram inseridas no acervo, com a devida referência bibliográfica. A coletânea conta, ainda, com algumas atividades adaptadas, isto é, trata-se de propostas constantes em outros materiais didáticos ou sugestões de livros teóricos que, após terem passado por avaliação da pesquisadora, sofreram alterações. Estas propostas também abarcam o acervo fazendo menção à devida referência bibliográfica.

Cabe mencionar, ainda, como foi feita a avaliação do teste cloze, chegando-se à nota de cada aluno. Após a realização dos testes, os dados foram tabulados em planilha Excel, sendo atribuída a seguinte pontuação: preenchimento de acordo com a palavra original: 2 pontos; preenchimento com termo sinônimo: 1 ponto; erro ou em branco: 0 ponto. Ressalta-se que foram considerados sinônimos os termos que, naquele contexto, possuíam um sentido semelhante ao original, e que não foi levado em conta o emprego da classe gramatical. Como o texto continha 50 lacunas, a pontuação máxima a ser atingida pelo estudante seria 100 pontos. 


\section{Análise dos dados coletados}

Nesta seção, são apresentados e analisados os resultados do pré-teste cloze, aplicado antes da interação com o acervo didático, e do pós-teste cloze, aplicado após a interação. O Gráfico 1, a seguir, apresenta o comparativo entre os escores dos estudantes do $5^{\circ}$.

Gráfico 1 - Resultados do teste cloze - 50 ano A e B

\section{Resultado da testagem - 5o ano A e B}

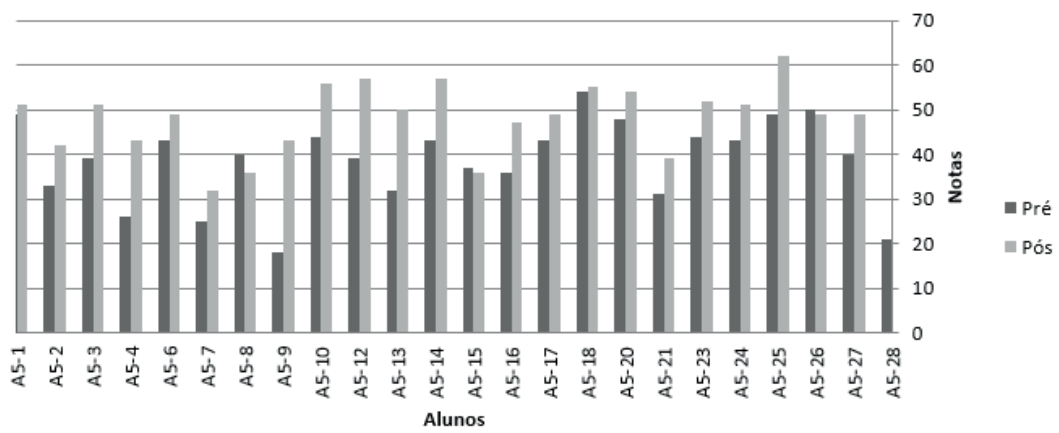

Fonte: Elaborado pelas autoras, 2017.

Considerando o total das duas turmas do $5^{\circ}$ ano, tem-se que a média no pré-teste foi de 38,62 e no pós-teste foi de 47,66. Esse dado revela que a média geral de notas dos alunos no pós-teste foi maior em relação ao pré-teste, o que significa que houve melhora dos índices de compreensão leitora após a interação com as atividades envolvendo o ensino das estratégias de leitura em $23,4 \%$. É um dado significativo em relação ao pouco tempo de interação.

Outro dado interessante é que a mediana das duas turmas foi de 40 no pré-teste e 49 no pós-teste. Essa medida indica que, em relação à centralidade dos índices, $50 \%$ estão situados abaixo do centro e os outros $50 \%$ estão acima. Embora tenha se observado uma mediana baixa, houve 
evolução do pré para o pós-teste. Além do mais, comparando-se esses resultados aos obtidos em estudos de Pereira (2008), pode-se constatar que os sujeitos deste estudo atingiram uma média adequada aos padrões de testagem do método cloze. Contudo, acredita-se que, se tiverem mais contato com os objetos digitais de aprendizagem, poderão alcançar a pontuação média trazida por Pereira (2008), que é de 6,0.

Outro aspecto que chama a atenção é o fato de tanto a média quanto a mediana representarem notas baixas, em termos absolutos, o que indica, numa análise abrangente, a deficiência em compreensão leitora e a fragilidade do trabalho realizado com a leitura. Mas indica, principalmente, o longo caminho a ser percorrido em se tratando do ensino e da aprendizagem da leitura. Sob essa ótica, o uso de metodologias ativas de ensino pode ser fundamental nesse processo.

Outro dado relevante é a amplitude, que revela a diferença entre a maior e a menor variável. No pré-teste foi de 36 e no pós-teste de 30, o que evidencia que no pós-teste ocorreu uma diferença menor entre o aluno que teve a menor nota e o que teve a maior nota, ou seja, houve menos disparidade entre os estudantes nos pós-testes.

O desvio padrão, que foi de 9,2 no pré-teste e 7,8 no pós-teste, teve uma modesta redução, evidenciando que, em relação à média, houve menos variação de escores. Outra medida realizada foi o coeficiente de variabilidade, que no pré-teste foi de $23,82 \%$ e no pós-teste, $16,38 \%$. Isso confirma a redução na variabilidade das notas.

Vale destacar também que o coeficiente de correlação entre o pré-teste e o pós-teste foi de 0,7 . Isso evidencia a proximidade das notas de um aluno no pré e no pós-teste. Por exemplo, o aluno A5-1 foi um dos que teve a melhor nota tanto no pré-teste quanto no pós-teste. Já os alunos A5-7 e A5-28 estão entre os alunos que tiveram a nota mais baixa no pré-teste e também no pós-teste. Isso revela, entre outros aspectos, a fidedignidade do teste aplicado. Moreira (2011) esclarece que a fidedignidade permite acurar se os dados coletados possuem estabilidade, reprodutibilidade ou precisão: 
Um instrumento de coleta de dados fidedignamente perfeito é um que se fosse aplicado duas vezes sob as mesmas circunstâncias nos forneceria os mesmos resultados. Como foi dito, a correlação é a ferramenta estatística básica na análise de fidedignidade de testes. Uma correlação 1,00 indicaria perfeita fidedignidade, enquanto a correlação 0,00 indicaria nenhuma fidedignidade. Correlações intermediárias indicariam diferentes níveis de fidedignidade (MOREIRA, 2011, p. 158).

A partir dessa citação, pode-se inferir que, estando o índice de correlação em 0,7, o teste aplicado neste estudo apresenta uma forte fidedignidade. Passa-se, a partir desse ponto, para uma análise dos resultados relativos ao trabalho desenvolvido no $8^{\circ}$ ano, conforme Gráfico 2, apresentado a seguir.

Gráfico 2 - Resultados do teste cloze - 8o ano A e B

Resultado da testagem - 8 ano A e B

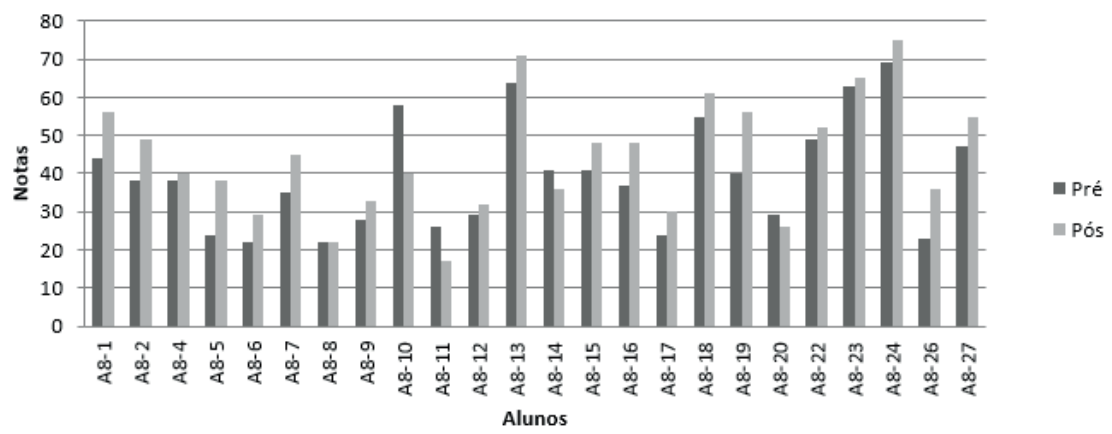

Fonte: Elaborado pelas autoras, 2017.

Avaliando a totalidade das duas turmas do $8^{\circ}$ ano, tem-se que a média no pré-teste foi de 39 e no pós-teste foi de 44, evidenciando uma melhora em relação ao pré-teste, o que significa evolução de $12,5 \%$ nos índices de compreensão leitora após a interação com as atividades.

Em relação à mediana, esta foi de 38 no pré-teste e 43 no pós-teste. Embora também tenha se observado uma mediana baixa, 
houve evolução do pré para o pós-teste. Mais uma vez, os baixos índices de média e mediana representam a deficiência em compreensão leitora e a fragilidade do trabalho realizado com a leitura. Esses dados convergem com a perspectiva de ensino que vem sendo desenvolvida, conforme evidenciado nas informações coletadas na entrevista.

Acerca da amplitude, que revela a diferença entre a maior e a menor variável, no pré-teste foi de 47 e no pós-teste de 58, o que evidencia que no pós-teste ocorreu uma diferença maior entre o aluno que teve a menor nota e o que teve a maior nota.

O desvio padrão, que foi de 14 no pré-teste e 15 no pós-teste, teve uma modesta elevação, evidenciando que, em relação à média, houve mais variação de escores, em termos absolutos. Já o coeficiente de variabilidade, que no pré-teste foi de $32 \%$, foi no pós-teste de $31 \%$. Isso confirma a redução na dispersão das notas, o que é positivo, pois diminuiu as diferenças entre os que apresentavam melhor desempenho e os que apresentavam menor desempenho em relação à compreensão leitora. Acredita-se que a abordagem adotada seguindo uma metodologia ativa de ensino pode ter contribuído nessa evolução. O que também pode ter contribuído nesse sentido foi a grande quantidade de trabalhos em grupo realizados nessas atividades, o que geralmente não é tão comum nas aulas de Língua Portuguesa. O estudo realizado por Mendes (2014) admite os resultados positivos das atividades grupais para a aprendizagem dos alunos.

Acerca do coeficiente de correlação, este foi de 0,9 , corroborando para a segurança científica do teste aplicado, conforme já estabelecido anteriormente, a partir de Moreira (2011).

Antes de concluir, é preciso considerar que a evolução da compreensão leitora tanto do $5^{\circ}$ ano quanto do $8^{\circ}$ ano não se deva, unicamente, ao trabalho com o acervo didático. Não se pode negligenciar que um dos motivos dessa evolução possa ser o fato de os alunos terem realizado o mesmo teste, pela segunda vez. Ou seja, ao realizarem o pré-teste, era a primeira experiência com o teste cloze, o que pode ter influenciado nos resultados do pós-teste, já que esta não era mais a primeira vez com esse tipo de atividade. Além desse elemento, certamente outros trabalhos 
desenvolvidos pelas professoras podem ter contribuído para a melhora da qualidade de leitura dos alunos, como, por exemplo, o próprio trabalho desenvolvido por elas ao longo das aulas.

\section{Considerações finais}

Ao longo deste estudo focalizou-se o ensino de estratégias de compreensão leitora no Ensino Fundamental na perspectiva das metodologias ativas de ensino. Buscou-se, basicamente, investigar estratégias de ensino, norteadas por metodologias ativas, que possam contribuir para o aprimoramento da compreensão leitora dos estudantes do $5^{\circ}$ e do $8^{\circ}$ anos do Ensino Fundamental. Daí surgiu o acervo didático, elaborado com base no aporte teórico estudado.

Objetivou-se, também, inserir esse material no planejamento didático de aulas de Língua Portuguesa dessas turmas envolvidas, de modo que pudessem ser investigados seus efeitos em relação à compreensão leitora dos alunos. Acerca desse aspecto e com base nos índices do teste cloze, pôde-se evidenciar que o acervo contribuiu para que houvesse evolução na habilidade de leitura dos estudantes. O percentual de evolução do $5^{\circ}$ ano foi de $23,4 \%$, ao passo que a evolução do $8^{\circ}$ ano foi de $12,05 \%$. Esses dados são significativos em relação ao pouco tempo de interação com o material. A partir disso, acredita-se que, se ao longo do Ensino Fundamental o ensino da leitura fosse norteado por estratégias de compreensão leitora a partir da perspectiva das metodologias ativas, os resultados seriam ainda melhores.

Em nenhum momento pretendeu-se comparar a evolução das duas turmas, mas cabe fazer um apontamento acerca desse aspecto. Considera-se que o maior índice de evolução tenha recaído sobre os alunos do $5^{\circ}$ ano em razão de a abordagem dessa turma, antes do contato com o acervo didático, afastar-se bastante da proposta deste trabalho. Em outras palavras, as estratégias da coletânea eram inovadoras para os alunos e, portanto, o efeito foi mais significativo. Já em relação ao $8^{\circ}$ 
ano, conforme evidenciado nas entrevistas com as professoras, a docente da turma já vinha adotando uma abordagem de ensino que se aproxima de uma perspectiva voltada para as estratégias de compreensão leitora. Dessa forma, o efeito da coletânea pode ter tido menos impacto.

Outro aspecto que pode ter interferido na diferença de resultados entre as duas turmas é o próprio teste cloze. No pré-teste, provavelmente foi a primeira vez que os alunos do $5^{\circ}$ ano tiveram contato com texto lacunado, em que precisavam inferir as palavras substituídas por lacunas. Já no pós-teste, a dificuldade pode ter sido um pouco menor em razão de já terem tido a experiência do pré-teste.

Alicerçado nesses resultados, é possível considerar que o acervo didático, constituído por estratégias de ensino norteadas por metodologias ativas, pode ser uma proposta de intervenção que possibilita uma mudança no rumo da abordagem de leitura que se tem visto nas aulas de Língua Portuguesa. Além disso, se o trabalho for conjugado a teorias consistentes, pode-se melhorar ainda mais a capacidade leitora dos estudantes.

Com isso, tal como mencionado ao longo deste trabalho, estará se contribuindo para a constituição de sujeitos críticos e atuantes na sociedade, já que a capacidade de leitura entre a população é um elemento que, na atual hierarquia de valores da sociedade, distingue notoriamente as pessoas. A consequência da desqualificação dos indivíduos em relação à habilidade de leitura é a exclusão de boa parte dos jovens de participar ativamente da sociedade, comprometendo, assim, seu desempenho frente às demandas do mundo do trabalho e da participação cidadã.

Vislumbra-se, assim, contribuir para a ampliação dos conhecimentos acerca do ensino de estratégias de leitura por meio de metodologias ativas de ensino. Ademais, este estudo oferece subsídios para os professores de Língua Portuguesa aprimorarem sua prática pedagógica e contribui para a formação de leitores ativos.

Diante das considerações feitas até aqui, pode-se considerar que a principal inovação deste trabalho está em buscar aproximar o ensino de estratégias de compreensão leitora sob a ótica das metodologias ativas de ensino. Com isso, espera-se ter contribuído para abrir caminhos 
para novas pesquisas. Ademais, entende-se que, seguindo a perspectiva de trabalho que aqui se apresenta, pode-se oferecer uma oportunidade para o aluno desenvolver o raciocínio, o pensamento crítico e as habilidades argumentativas, que são essenciais para qualquer cidadão exercer seus direitos e deveres em sociedade.

\section{Referências}

ANASTASIOU, L. G. C.; ALVES, L. P. Estratégias de ensinagem. In: ANASTASIOU, L. G. C.; ALVES, L. P. (Orgs.). Processos de ensinagem na universidade: pressupostos para as estratégias de trabalho em aula. 3. ed. Joinville: Univille, 2004. p. 67-100.

BERBEL, N. A. N. As metodologias ativas e a promoção da autonomia de estudantes. Semina: Ciências Sociais e Humanas, Londrina, v. 32, n. 1, p. 25-40, jan./jun. 2011.

BRASIL. Ministério da Educação e Cultura. Instituto Nacional de Estudos e Pesquisas Educacionais Anísio Teixeira. Prova Brasil: Boletim de Desempenho da escola. Brasília: INEP, 2015. Disponível em: <http://sistemasprovabrasil.inep. gov.br/provaBrasilResultados/view/boletimDesempenho/boletimDesempenho. seam>. Acesso em: 22 jun. 2016.

DEWEY, J. Vida e educação. 10. ed. São Paulo: Melhoramentos, 1978.

DIESEL, A.; MARCHESAN, M.; MARTINS, S. N. Metodologias ativas de ensino na sala de aula: um olhar de docentes da educação profissional técnica de nível médio. Revista Signos, Lajeado, ano 37, n. 1, 2016.

FORNECK, K. et al. Um click na leitura: objetos virtuais de compreensão textual. Lajeado: Ed. da Univates, 2015. [E-book].

FREIRE, P. Pedagogia da autonomia: saberes necessários à prática educativa. São Paulo: Paz e Terra, 1996.

HENGEMÜHLE, A. Formação de professores: da função de ensinar ao resgate da educação. 3. ed. Petrópolis: Vozes, 2014. 
INOVAÇÃO. In: PRIBERAM INFORMÁTICA. Dicionário Priberam da Língua Portuguesa. (C) 2016. Disponível em: <https://www.priberam.pt/DLPO/inova\%C3\%A7\%C3\%A3o > Acesso em: 22 jun. 2016.

KATO, M. O aprendizado da leitura. São Paulo: Martins Fontes, 1985.

LEFFA, V. J. Aspectos da leitura. Porto Alegre: Sagra-DC-Luzzatto, 1996.

MANGILI, P. A. Hipertexto no Ensino Fundamental II: Estratégias de Leitura. 2011. 146 f. Dissertação (Mestrado Acadêmico em Língua Portuguesa) — Pontifícia Universidade Católica de São Paulo, São Paulo, 2011.

MEDEIROS, A. Docência na socioeducação. Brasília: Universidade de Brasília, Campus Planaltina, 2014.

MENDES, E. S. Modelagem computacional e simulações em física usando o software Modellus: uma abordagem alternativa no ensino de cinemática. 2014. Dissertação (Mestrado) - Curso de Ensino de Ciências Exatas, Centro Universitário UNIVATES, Lajeado, 2014. Disponível em: <http://hdl.handle.net/10737/803〉. Acesso em: 10 out. 2016.

MORAES, J. Criar leitores: para professores e educadores. Barueri: Manole, 2013. MOREIRA, M. A. Metodologias de pesquisa em ensino. São Paulo: Livraria da Física, 2011. PEREIRA, V.W. Compreensão leitora de alunos do ensino médio. ReVEL, v. 6, n. 11, ago. 2008. PEREIRA, V. W. (Coord.). Relatório do Projeto: Avaliação da Compreensão Leitora de Alunos do Ensino Médio: Escores em Correlação - ACOL. PUCRS, 2005.

PORTO, C. C. R. F. Práticas de Ensino de Compreensão de Leitura e Conhecimentos de Alunos do Último Ano do Ensino Fundamental I. 2011. 220 f. Dissertação (Mestrado Acadêmico em Educação) — Universidade Federal de Pernambuco, Recife, 2011.

RUARO, D. A. Problematização da Prática Reflexiva de Professores de Língua Portuguesa na Sala de Aula. Curitiba: Intersaberes, 2013.

SACRISTÁN, J. G. A educação que ainda é possivel: ensaios sobre uma cultura para a educação. Porto Alegre: Artmed, 2008. 
THIESEN, J. S. A interdisciplinaridade como um movimento articulador no processo ensino-aprendizagem. Revista Brasileira de Educação, v. 13, n. 39, set./dez. 2008. p. 546-554. SOLÉ, I. Estratégias de leitura. 6. ed. Porto Alegre: Artmed, 1998.

SOUZA, C. S.; IGLESIAS, A. G.; PAZIN-FILHO, A. Estratégias inovadoras para métodos de ensino tradicionais - aspectos gerais. Medicina, v. 47, n. 3, p. 284-292, 2014.

Recebido: 26/08/2017

Received: 08/26/2017

Recibido: 26/08/2017

Aprovado: 04/10/2017

Approved: 10/04/2017

Aprobado: 04/10/2017 